\title{
SABRINA CARUSO CHATE
}

Situação epidemiológica da brucelose bovina no Estado do Mato Grosso do Sul, Brasil

São Paulo

2010 


\section{SABRINA CARUSO CHATE}

Situação epidemiológica da brucelose bovina no Estado do Mato Grosso do Sul, Brasil

Tese apresentada ao Programa de Pós Graduação em Epidemiologia Experimental Aplicada às Zoonoses da Faculdade de Medicina Veterinária e Zootecnia da Universidade de São Paulo para obtenção do título de Doutor em Ciências

Departamento:

Medicina Veterinária Preventiva e Saúde Animal

Área de concentração:

Epidemiologia Experimental Aplicada às Zoonoses

Orientador:

Prof. Dr. José Soares Ferreira Neto

São Paulo

2010 
Autorizo a reprodução parcial ou total desta obra, para fins acadêmicos, desde que citada a fonte.

\section{DADOS INTERNACIONAIS DE CATALOGAÇÃO-NA-PUBLICAÇÃO}

(Biblioteca Virginie Buff D’Ápice da Faculdade de Medicina Veterinária e Zootecnia da Universidade de São Paulo)

T.2257 Chate, Sabrina Caruso

FMVZ Situação epidemiológica da brucelose bovina no Estado do Mato Grosso do Sul, Brasil / Sabrina Caruso Chate. -- 2010.

$$
43 \mathrm{f} \text { : : il. }
$$

Tese (Doutorado) - Universidade de São Paulo. Faculdade de Medicina Veterinária e Zootecnia. Departamento de Medicina Veterinária Preventiva e Saúde Animal, São Paulo, 2010.

Programa de Pós-Graduação: Epidemiologia Experimental Aplicada às Zoonoses.

Área de concentração: Epidemiologia Experimental Aplicada às Zoonoses.

Orientador: Prof. Dr. José Soares Ferreira Neto.

1. Bovinos. 2. Brucelose. 3. Prevalência. 4. Mato Grosso do Sul, Brasil. I. Título. 


\section{ERRATA}

CHATE, S.C. Situação epidemiológica da brucelose bovina no Estado do Mato Grosso do Sul, Brasil. [Epidemiological situation of bovine brucellosis in Mato Grosso do Sul State, Brazil]. 2010. $43 \mathrm{f}$. Tese (Doutorado em Ciências)- Faculdade de Medicina Veterinária e Zootecnia, Universidade de São Paulo, São Paulo, 2010.

$$
\text { Folha }
$$

Parágrafo Linha

Onde se lê

Leia-se

Ficha catalográfica

Resumo

$3^{a}$

$1^{\mathrm{a}}$

$43 \mathrm{f}$.

$42 \mathrm{f}$.

Abstract

$1^{\mathrm{a}} \quad 3^{\mathrm{a}}$

$43 \mathrm{f}$.

$42 \mathrm{f}$. 


\section{FOLHA DE AVALIAÇÃO}

Nome: CHATE, Sabrina Caruso

Título: Situação epidemiológica da brucelose bovina no Estado do Mato Grosso do Sul, Brasil

Tese apresentada ao Programa de Pós Graduação em Epidemiologia Experimental Aplicada às Zoonoses da Faculdade de Medicina Veterinária e Zootecnia da Universidade de São Paulo para obtenção do título de Doutor em Ciências

Data:

Banca Examinadora

Prof. Dr:

Instituição:

Assinatura: Julgamento:

Prof. Dr: Instituição:

Assinatura: Julgamento:

Prof. Dr: Instituição:

Assinatura: Julgamento:

Prof. Dr: Instituição:

Assinatura: Julgamento:

Prof. Dr: Instituição:

Assinatura: Julgamento: 


\section{DEDICATÓRIA}

Dedico esse trabalho a toda a minha família, sempre presente em minha vida.

Especialmente ao meu marido, Cristiano, pelo amor, companheirismo e dedicação.

Aos meus filhos, Maria Eduarda, João Vítor e Valentina, por terem me transformado em uma pessoa muito melhor.

A minha mãe, Sonia, por seu apoio, carinho e paciência.

Ao meu tio, Salvador, pelo incentivo e por sua generosidade.

A minha tia, Suzi, pela ajuda a qualquer hora e sempre que necessária, pela companhia e pelo carinho.

Aos meus irmãos, Rodrigo e Guilherme, pela amizade e pela união.

Ao meu pai, José Eduardo, que certamente ilumina minha vida.

Ao meu avô, Miguel, que se sentiria muito orgulhoso. 


\section{AGRADECIMENTOS}

A Deus, por estar presente em minha vida, me transmitindo força, coragem, persistência e sabedoria.

Ao Prof. Dr. José Soares Ferreira Neto, pela confiança, paciência e acima de tudo compreensão.

Aos colegas do LEB, pelo tempo de convivência e por toda ajuda.

À Jussélia, por todo apoio, amizade e ajuda.

Às amigas Marianna Matrone, Roberta Crudo Bellucci , Patrícia Borelli Noronha e Marta Maria C. P. Lupi, pelo apoio e pela ajuda imprescindível.

Às bibliotecárias, em especial, à Elza Faquim, pela importante ajuda.

Á Gisele Oliveira de Souza e Zenaide Maria de Morais pela sempre disponibilidade, amizade e ensinamentos.

Aos professores e funcionários do VPS, pela oportunidade e pelos ensinamentos.

Ao CNPQ pela oportunidade e pelo apoio financeiro.

Aos veterinários do IAGRO e do MAPA pela realização da parte prática do projeto e pela ajuda no esclarecimento das dúvidas.

Á todos aqueles que participaram direta ou indiretamente deste trabalho. 


\section{RESUMO}

CHATE, S.C. Situação epidemiológica da brucelose bovina no Estado do Mato Grosso do Sul, Brasil. [Epidemiological situation of bovine brucellosis in Mato Grosso do Sul State, Brazil]. 2010. 43 f. Tese (Doutorado em Ciências)- Faculdade de Medicina Veterinária e Zootecnia, Universidade de São Paulo, São Paulo, 2010.

Para dar suporte à implementação do Programa Nacional de Controle e Erradicação da Brucelose e Tuberculose no Estado do Mato Grosso do Sul, foi realizado um estudo para caracterizar a situação epidemiológica da brucelose bovina. Considerando as características regionais da produção pecuária, foram definidos três estratos a serem estudados no Estado: Pantanal corte, Planalto corte e Planalto leite, esse último subdividido em Bolsão, Campo Grande e Dourados. Em cada estrato foram amostradas aleatoriamente propriedades, e dentro dessas foi escolhido, também de forma aleatória, um número pré-estabelecido de animais, dos quais foi obtida uma amostra de sangue. No total foram amostrados 14.849 animais, provenientes de 1.004 propriedades. Em cada propriedade amostrada foi aplicado um questionário epidemiológico indagando sobre suas características e também sobre a observação de transtornos reprodutivos que poderiam estar associados à infecção brucélica. O teste utilizado foi o do Antígeno Acidificado Tamponado. $O$ rebanho foi considerado positivo se pelo menos um animal fosse reagente à prova sorológica. Para o Estado, a prevalência de focos foi de 41,5\% [36,5\% - 44,7\%]. As prevalências de focos e animais nos estratos foram respectivamente de: 59,0\% [52,8\% - 64,9\%] e $12,6 \%$ [9,1\% - 17,2\%] para o estrato Pantanal corte, 40,6\% [35,8\% - 45,5\%] e 4,5\% [2,1\% - 9,0\%] para o Planalto corte. No estrato Planalto leite, a prevalência de focos foi de $33,1 \%$ [28,4\% - 38,1\%]. Os fatores associados à condição de foco foram: ter $\geq 500$ vacas ( $O R=2,46[1,81-3,34]$ ), a ocorrência de bezerros fracos $(O R=1,20[0,87-1,65])$ e a inseminação artificial $(O R=0,71[0,50$ $-1,01])$.

Palavras-chave: Bovinos. Brucelose. Prevalência. Mato Grosso do Sul, Brasil. 


\begin{abstract}
CHATE, S.C. Epidemiological situation of bovine brucellosis in Mato Grosso do Sul State, Brasil. [Situação epidemiológica da brucelose bovina no Estado do Mato Grosso do Sul, Brasil]. 2010. 43 f. Tese (Doutorado em Ciências)- Faculdade de Medicina Veterinária e Zootecnia, Universidade de São Paulo, São Paulo, 2010.
\end{abstract}

To support the planning and implementation of the National Program for the Control and Eradication of Brucellosis and Tuberculosis in the State of Mato Grosso do Sul, a study to characterize the epidemiological status of bovine brucellosis was carried out. The State was divided in three regions. Herds were randomly sampled in each region, and a pre-established number of animals were sampled in each of these herds. A total of 14.849 serum samples from 1.004 herds were collected. In each herd it was applied an epidemiological questionnaire focused on herd traits as well as clinical signs that could be associated with the brucellosis infection. The serum samples were tested for antibodies against Brucella spp. by the Rose-Bengal Test (RBT). The herd was considered positive if at least one animal tested positive. The prevalence of infected herds at the State level were $41.5 \%$ [36.5\% - 44.7\%]. The prevalence of infected herds at the Regional level were respectively: 40.6\% [35.8\% 45.5\%] for the Beef Planalto region, 59.0\% [52.8\% - 64.9\%] for the Beef Pantanal region and $33.1 \%$ [28.4\% - 38.1\%] for the Dairy Planalto region. The factors associated with the presence of the infection were: herd size bigger than 500 cows $(\mathrm{OR}=2.46[1.81-3.34])$, occurrence of weak calf $(\mathrm{OR}=1.20[0.87-1.65])$ and use of artificial insemination $(\mathrm{OR}=0.71[0.50-1.01])$.

Keywords: Brucellosis. Cattle. Prevalence. Mato Grosso do Sul, Brazil. 


\section{UNIVERSIDADE DE SAOO PAULO \\ Faculdade de Medicina Veterinaria e Zootcona

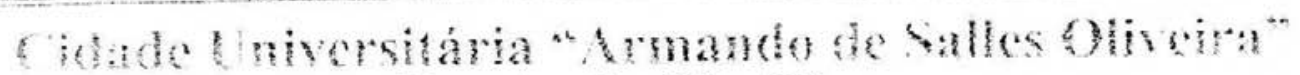

Comissão Bioética

\section{CERTIFICADO}

Certificamos que o Projeto intitulado "Epidemiologia e controle da brucelose e tuberculose bovinas no Brasil: bases para as intervenções", protocolo $n^{\circ} 441 / 2004$, utilizando 180 hamsters, sob a responsabilidade do Prof. Dr. José Soares Ferreira Neto, está de acordo com os princípios éticos de experimentação animal da Comissão de Bioética da Faculdade de Medicina Veterinária e Zootecnia da Universidade de São Paulo e foi aprovado pela referida Comissão em sessão de $14 / 04 / 04$.

We certify that the Research "Epidemiology and contrl of the bovine brucellosis and tuberculosis in Brazil: basis for the interventions" protocol number 441/2004, utilizing 180 hamsters, under the responsibility of Prof Dr. José Soares Ferreira Neto, agree with Ethical Principles in Animal Research adopted by Bioethic Commission of the Faculty of Veterinaty Medicine and Zootechny of University of São Paulo and was approved in $04 / 14 / 2004$ meeting.

Sào Paulo, 16 de abril de 2004

Prof Dra Julia Marda Materalce Presidente da Comissão de Bioética FMYZ/USP 


\section{LISTA DE FIGURAS}

Figura 1 - Mapa do Estado do Mato Grosso do Sul evidenciando o estrato corte, dividido nas regiões Pantanal e Planalto- São Paulo-2009.

Figura 2 - Mapa do Estado do Mato Grosso do Sul evidenciando o estrato leite, composto pelas bacias leiteiras Bolsão, Campo Grande e Dourados- São Paulo2009 .30 


\section{LISTA DE QUADROS}

Quadro 1 - Principais estudos de prevalência de brucelose realizados no

Estado

do Mato Grosso do Sul - São Paulo-2009.

15 


\section{LISTA DE TABELAS}

Tabela 1 - Dados censitários da população bovina do Estado do Mato Grosso do Sul em 1998, segundo os estratos (dados do cadastro do IAGRO)- São Paulo2009 30

Tabela 2 - Prevalência de focos de brucelose nos estratos do Estado do Mato Grosso do Sul - São Paulo-2009. 31

Tabela 3 - Prevalência de brucelose nos bovinos dos estratos do Estado do Mato Grosso do Sul -São Paulo-2009. 31

Tabela 4 - Análise univariada dos possíveis fatores associados à condição de foco de brucelose bovina no Estado do Mato Grosso do Sul - São Paulo2009 32

Tabela 5 - Modelo final da regressão logística multivariada para os fatores associados à condição de foco de brucelose bovina no Estado do Mato Grosso do Sul -São Paulo- 2009 


\section{LISTA DE SÍMBOLOS}

$\%$.

Porcentagem

${ }^{\circ} \mathrm{C}$. Graus Celsius

$\chi^{2}$. Teste do Quiquadrado 


\section{SUMÁRIO}

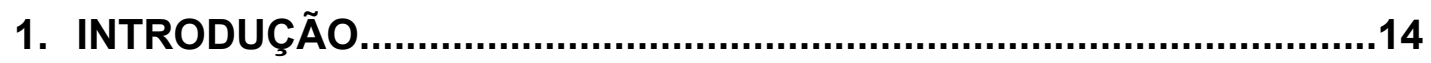

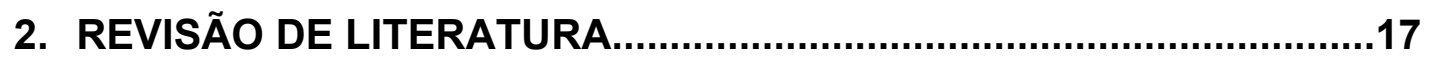

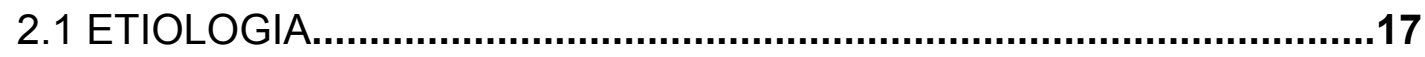

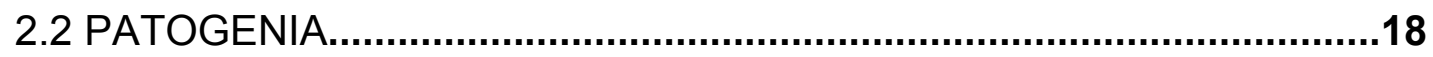

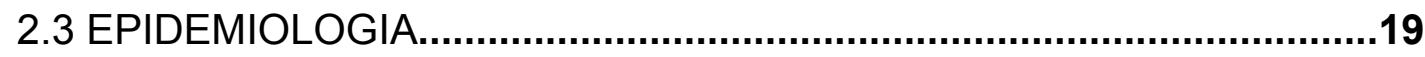

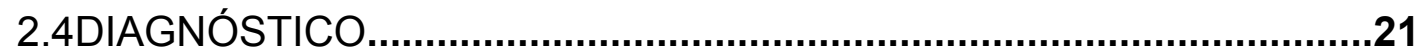

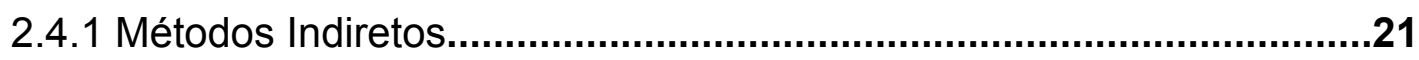

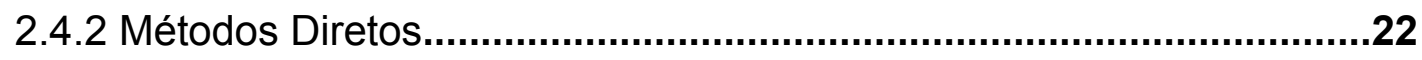

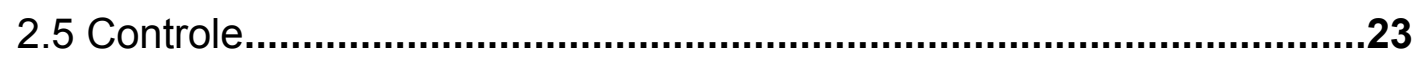

3. MATERIAL E MÉTODOS

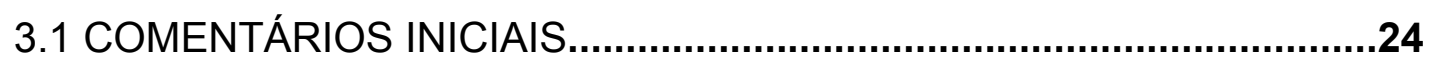

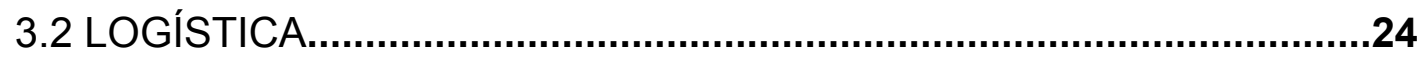

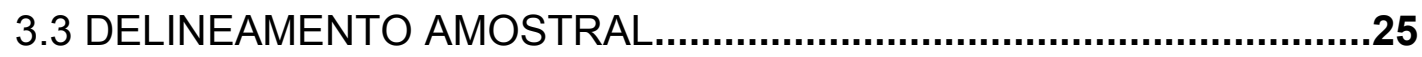

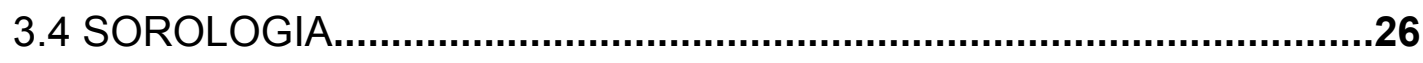

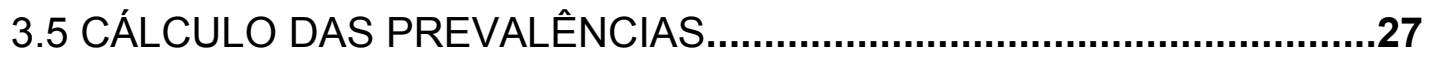

3.6 ESTUDO DOS FATORES DE RISCO.................................................27

4. RESULTADOS

4.1 CIRCUITOS PRODUTORES............................................................29

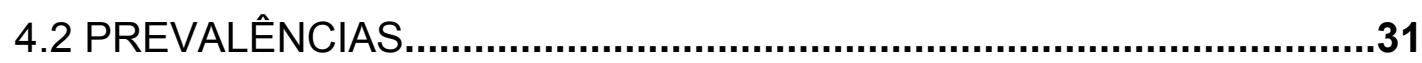

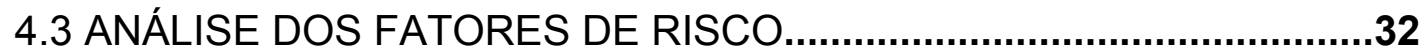

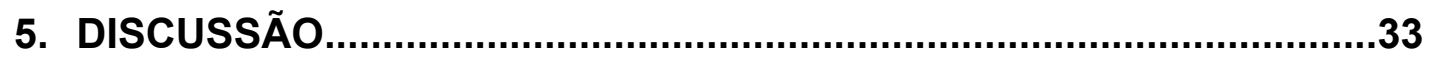

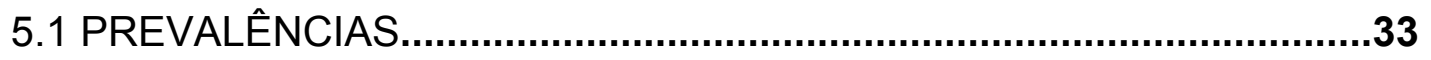

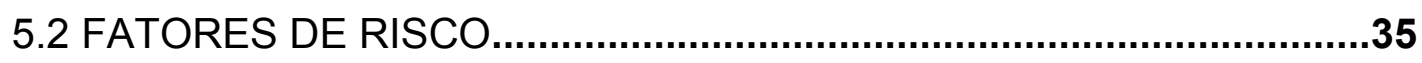

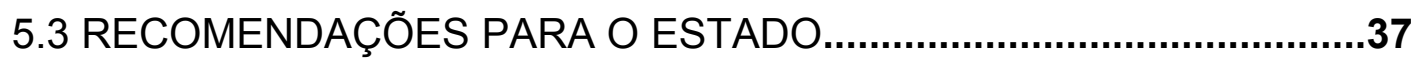

6. REFERÊNCIAS BIBLIOGRÁFICAS...............................................38 


\section{INTRODUÇÃO}

O Estado do Mato Grosso do Sul está localizado na região Centro- Oeste do Brasil e sua extensão territorial corresponde a $18 \%$ da região Centro-Oeste e 4,19\% do Brasil, com 358.158,7 km². O Pantanal sul-mato-grossense ocupa uma área de $89.318 \mathrm{~km}^{2}$, correspondente a $25 \%$ do território estadual. O Estado é dividido em duas grandes bacias hidrográficas: a do Rio Paraná, constituída basicamente de chapadões, planaltos e vales, e a do Rio Paraguai, constituída de patamares, depressões e depressões inter-patamares, formando o Pantanal nas regiões chaquenha e pantaneira (MATO GROSSO DO SUL, 2008)

Faz fronteira ao sul com dois países: Bolívia e Paraguai. Com posição geográfica privilegiada, ele também faz divisa com cinco Estados brasileiros: Minas Gerais, São Paulo, Paraná, Goiás e Mato Grosso (MATO GROSSO DO SUL, 2008).

O processo de pecuarização do Estado teve início com colonos espanhóis, que se instalaram no Pantanal sul-mato-grossense a partir de 1600. Mais tarde, com a fundação das missões jesuíticas do Itaim, novos rebanhos foram sendo introduzidos (ESSELIN, 2003).

Juntamente com a erva mate e a soja, a pecuária contribuiu para incorporar o Estado ao mercado nacional (ESSELIN, 2003).

O efetivo bovino do Estado do Mato Grosso do Sul é de 24,5 milhões, correspondente a $12 \%$ do rebanho brasileiro, que totaliza 207 milhões de cabeças (IBGE, 2005). O número total de propriedades é de 38.346, divididas entre as regiões do Pantanal e Planalto.

As propriedades da região do Pantanal, formada por 8 municípios, são essencialmente de corte, enquanto na região do Planalto, formada por 71 municípios, existem propriedades de exploração de corte e de leite (Bacias leiteiras do Bolsão, de Campo Grande e de Dourados).

A IAGRO (Agência Estadual de Defesa Sanitária Animal e Vegetal do MS) foi criada em 1978, após a implantação do Estado. Hoje dispõe de 80 escritórios locais, distribuídos por todos os seus municípios, 11 escritórios regionais e uma sede central. O combate à doença começou a se estruturar de forma mais organizada no Estado a partir de julho de 2002, com a implementação do programa de vacinação 
obrigatória definido no Programa Nacional de Controle e Erradicação da Brucelose e Tuberculose - PNCEBT (Comunicação pessoal*).

A Brucella spp é uma bactéria Gram-negativa, intracelular facultativa que infecta animais domésticos e silvestres e também humanos. Nos animais a doença está relacionada a problemas reprodutivos e no homem geralmente produz quadros de infecção generalizada (PAULIN; FERREIRA NETO, 2003). Este gênero de bactérias se replica em fagócitos mononucleares do hospedeiro, inibindo os mecanismos extracelulares da resposta imune (SALDARRIAGA et al., 2002).

A brucelose bovina, causada pela Brucella abortus, é uma das zoonoses mais difundidas no mundo e alvo de programas de controle e erradicação em muitos países. Foram poucos os estudos de grande dimensão, direcionados ao esclarecimento da situação epidemiológica da brucelose no Estado. Os principais foram sumarizados no quadro 1.

\begin{tabular}{|c|c|c|c|c|c|c|}
\hline ano da coleta & região do estudo & $\begin{array}{c}\text { tipologia } \\
\text { propriedade }\end{array}$ & teste utilizado & $\begin{array}{c}\text { planejamento } \\
\text { amostral }\end{array}$ & prevalência & autores (ano) \\
\hline 2003-2004 & planalto do MS & corte e leite & AAT + 2-ME & houve & $\begin{array}{c}37,3 \% \text { de focos } \\
5,6 \% \text { de animais }\end{array}$ & Monteiro et al, 2006 \\
\hline 2001 & MS & & AAT & não houve & $8,6 \%$ de animais & Almeida, 2001 \\
\hline $1994-1996$ & pantanal do MS & corte & AAT + 2-ME & não houve & $3,43 \%$ de animais & Pellegrin et al, 1999 \\
\hline $1982-1984$ & pantanal do MS & corte & AAT & não informa & $10,19 \%$ de animais & Cavalléro, 1998 \\
\hline 1975 & $\begin{array}{r}\text { antigo estado de Mato } \\
\text { Grosso }\end{array}$ & corte eleite & SARP & houve & $22,9 \%$ de focos & B,25\% de animais \\
\hline
\end{tabular}

Quadro 1 Principais estudos de prevalência de brucelose realizados no Estado do Mato Grosso do Sul.

Além desses estudos principais, existem três outras fontes com dados sobre a situação da brucelose bovina.

A IAGRO analisou as notificações dos testes de soroaglutinação rápida em placa de 1981 a 1984 e verificou 10.939 bovinos reagentes em 326.316 testados, resultando em uma freqüência de 3,35\% (LEMOS, 1998).

Para o período de 1982 a 1984, a Universidade Federal de MS reportou 206 bovinos reagentes à sorologia para brucelose em 2.276 examinados, perfazendo uma freqüência 8,08\% (LEMOS, 1998). 
Pellegrin et al (1996) reportaram soropositividade de 6,9\% em 198 touros e de $2 \%$ em 561 matrizes criadas na região do Pantanal sul-mato-grossense no período de 1994 a 1995.

A partir de 2007, Mato Grosso do Sul foi incluído no Projeto de Modernização da Defesa Agropecuária, conduzido pelo MAPA. Para isso, foi firmado o Convênio MA/SDA N. ${ }^{\circ}$ DFA/MS 003-00/97 que incluiu entre suas metas a realização de um grande estudo de prevalência para brucelose bovina no Estado. O referido estudo foi realizado em 1998, com uma metodologia bastante parecida com a proposta em 2003 para os demais Estados da União, mas os resultados foram tratados de maneira bastante simples e utilizados para a produção de um relatório final de prestação de contas do mencionado Convênio. Assim, o Estado resolveu não realizar o novo estudo proposto em 2003, pois o de 1998 seria suficiente para se conhecer a situação epidemiológica da doença antes da implementação do PNCEBT. Isso faz sentido, pois a brucelose é uma doença crônica, de difusão lenta e, portanto, pouco suscetível a grandes modificações na sua distribuição e freqüência no curto ou médio prazo. Então, optou-se por tomar os dados produzidos em 1998 e tratá-los conforme a metodologia do estudo de 2003, o que permitirá uma melhor implementação e gestão do PNCEBT em Mato Grosso do Sul. 


\section{REVISÃO DE LITERATURA}

\subsection{ETIOLOGIA}

De acordo com a OIE (Office International des Epizooties), FAO (Food and Agriculture Organization) e WHO (World Health Organization), a brucelose ainda é uma das mais importantes zoonoses disseminadas pelo mundo (POESTER; GONÇALVES; LAGE, 2002).

A Brucela é uma bactéria intracelular facultativa, Gram-negativa que pode infectar muitas espécies animais e o homem. São cocobacilos curtos, pequenos e pleomórficos, não formam cápsulas ou esporos e nem se movimentam ativamente(PAULIN; FERREIRA NETO, 2003; RIEMANN; CLIVER, 2006; CHU; WEYANT, 2003).

O gênero Brucella compreende 6 espécies: B melitensis, B. abortus, B. suis e B.neotomae (grupo das lisas ou clássicas), B. ovis, B.canis (grupo das rugosas),No grupo das lisas ou clássicas algumas espécies são subdivididas em vários biovares ou biótipos (B. melitensis: 3; B. abortus: 7; B. suis: 4) que se identificam principalmente por testes bioquímicos (PAULIN; FERREIRA NETO, 2003; CIPOLLA et al.,2004; LAGE, 2006; ALTON et al., 1975). Recentemente, foram isoladas de mamíferos marinhos, duas novas espécies de Brucella, descritas através diferenciação fenotipica e de característica moleculares baseadas no polimorfismo do DNA no locus omp2 e preferência por hospedeiros, a B. cetaceae e B. pinnipidiae (CLOECKAERT et al., 2003).

As variantes lisas ou rugosas são reconhecidas através da morfologia da colônia e para algumas espécies quanto à virulência. A morfologia está relacionada com a composição do lipopolissacarídeo na membrana celular. As lisas possuem lipídeo $\mathrm{A}$, núcleo oligossacáride e cadeia $\mathrm{O}$, já as rugosas possuem apenas lipídeo $\mathrm{A}$ e parte do núcleo oligossacáride (PAULIN; FERREIRA NETO, 2003; LAGE, 2006). Para algumas espécies de Brucella spp, o microorganismo virulento típico forma uma colônia lisa e transparente e tende sofrer mutação para forma rugosa, que é menos virulenta.

A constituição da parede celular das brucelas confere a elas uma resistência importante ao meio ambiente. A associação de presença de umidade, sombreamento e baixas temperaturas aumentam a sobrevivência do agente no meio 
ambiente, ampliando sua chance de alcançar um novo suscetível. A luz solar direta diminui sua sobrevivência (PAULIN; FERREIRA NETO, 2003). Os métodos de pasteurização ou a fervura inativam a bactéria, que também é sensível a vários grupos de desinfetantes químicos (LAGE, 2006).

\subsection{PATOGENIA}

As principais portas de entrada da B. abortus são as mucosas oral, nasal, genital e ocular. Após a penetração na mucosa, as bactérias são fagocitadas, multiplicam-se nos linfonodos regionais e a partir daí poderão disseminar-se pela via hemática e linfática, albergando-se nos tecidos ricos em células mononucleares fagocitárias, podendo sobreviver por longos períodos dentro dos fagócitos, escapando assim da resposta imune (LAGE, 2006).

Uma vez que a Brucella spp é capaz de replicar-se intracelularmente, a resposta imune mediada por células é a mais importante nos fenômenos da relação hospedeiro parasita. A patogenia da infecção por Brucella spp é muito complexa, dependendo da espécie do microrganismo e do hospedeiro envolvidas. Dentre os elementos da imunidade celular têm destaque os macrófagos, as citocinas tipo Th 1 e as células citotóxicas (SALDARRIAGA et al., 2002).

Importante lembrar, que esta bactéria move-se através dos vasos linfáticos e se desloca pelos órgãos através da corrente sanguínea, instalando-se preferencialmente em baço, linfonodos, fígado, aparelho reprodutor masculino, úbere e útero. A Brucella tende a se multiplicar no útero de animais suscetíveis, onde seu crescimento é favorecido pela presença da substância eritritol, produzido no feto e nas membranas circundantes. As lesões necrótico-inflamatórias placentárias impedem a passagem de nutrientes e oxigênio da mãe para o feto, provocando assim, o aborto (TORTORA, 2000; LAGE, 2006). Em geral o aborto se dá na segunda metade da prenhez, causando retenção placentária ou metrites que podem ser causa de infertilidade permanente (ACHA; SZYFRES, 2001). O eritritol é um álcool poli-hídrico de quatro carbonos produzidos a partir dos líquidos alantoideano e amniótico bovino (PEARCE et al., 1961). Este álcool, não está presente na placenta humana (CARTER; CHENGAPPA, 1991).

A resistência de bovinos à infecção por Brucella pode ser influenciada pela idade, sexo e potencial reprodutivo de cada animal. Fêmeas em gestação são mais 
suscetíveis à infecção do que as jovens. Estas podem infectar-se por contato com fetos abortados ou placentas contaminadas com a bactéria (THOEN; ENRIGHT, 1988). Em touros, ocasionalmente a infecção localiza-se nos testículos, epidídimo ou vesícula seminal formando abscessos (IKRAM; HILL, 1991).

Nos bovinos infectados, a eliminação do agente se dá por descargas uterinas, sêmen e fezes. Quando o animal não está prenhe, excreta bactéria no leite (TORTORA, 2000), duas semanas após o parto ou abortamento, podendo persistir por meses. Com a expulsão do feto, no parto ou abortamento, uma grande quantidade de bactérias é eliminada para o meio ambiente, contaminando pastagens, água e alimentos.

O risco da transmissão venérea pela monta natural é muito baixo, porém alto pela inseminação artificial (PAULIN; FERREIRA NETO, 2003). As principais formas de transmissão para humanos é através do consumo de alimentos lácteos contaminados, contato direto/indireto com animais infectados e exposição acidental em laboratório que trabalha com o agente (MARIANELLI et al., 2007).

\subsection{EPIDEMIOLOGIA}

A Brucella abortus reconhecida primeiramente por Bang em 1897 (CARTER; CHENGAPPA, 1991), tem distribuição mundial, concentrando-se principalmente nos países em desenvolvimento da África, América do Sul, Oriente Médio e Ásia (PAULIN; FERREIRA NETO, 2003).

A Brucelose é uma zoonose re-emergente no mundo, causadora de grandes perdas econômicas diretas, relacionadas com a diminuição da performance reprodutiva nos animais de produção. Estimativas apontam a brucelose como a responsável pela diminuição na produção de leite e de carne e na produção de bezerros (LAGE, 2006).

A brucelose bovina, causada pela Brucella abortus, é a infecção mais freqüente no Brasil, sendo seguida pela Brucella suis, em porcos. O impacto econômico da brucelose bovina no país foi estimado em 32 milhões de dólares anuais (POESTER; GONÇALVES; LAGE,2002).

Os prejuízos estão relacionados à menor produção de leite e carne, redução no valor dos animais e produtos animais oriundos de regiões infectadas, perda de 
mercados, custos do tratamento da doença em humanos (OIE,1987; OMS,1986; BENENSON,1983; GARCIA-CARRILO,1990).

A brucelose bovina acarreta em redução da produção leiteira de 20 a 25\%; redução da produção de carne de 10 a 15\%; perda de 15\% de bezerros em decorrência de aborto; aumento de $30 \%$ na necessidade de reposição de animais em rebanhos infectados e aumento do intervalo entre partos de 11,5 para 20 meses (FARIA,1984).

A brucelose bovina no Brasil é conhecida desde 1922 e a bactéria causadora foi isolada de fetos abortados de bovinos no Estado de São Paulo em 1930 (MELLO, 1950). Garcia-Carrillo (1987) apud POESTER et al., 2002, verificou a predominância dos biovares 1, 2 e 3 de B. abortus nos bovinos brasileiros, esta informação foi confirmada por Megid et al. em 2005, em um estudo realizado para caracterização dos biovares de Brucella abortus em bovinos abortados e fetos de búfalos d'água evidenciando também a infecção por B. abortus em búfalos d'água no país.

O estudo nacional realizado em 1977, revelou as prevalências de cada região: norte 4,1\%; noroeste 2,5\%; centro-oeste $6,8 \%$; sudeste $7,5 \%$ e sul $4,0 \%$ (BRASIL,1977). Poucos estudos foram realizados após este, e demonstraram que a situação não se alterou muito desde 1977. No estado do Rio Grande do Sul, como resultado de um programa de vacinação eficiente, a prevalência diminuiu de 2,0\% em 1977 para 0,3\% em 1986. Em Santa Catarina, houve um aumento de 0,2\% em 1977 para 0,6\% em 1996. No Estado do Mato Grosso do Sul, a prevalência permaneceu estável entre 1977 e 1998, em 6,3\%. Em Minas Gerais, a prevalência diminuiu de 7,6\% em 1977 para 6,7\% em 1980 (CASTRO,1982). De acordo com dados oficiais, a prevalência da brucelose bovina no Brasil sofreu um aumento de 4,0\% para 5,0\% no período de 1989 - 1998 (BRASIL,2001).

Dentre as perdas indiretas, vale lembrar que é a mais freqüente infecção bacteriana adquirida em laboratório, causando doenças em humanos com sinais inespecíficos, afetando vários órgãos (DAHOUK et al., 2003).

A alta incidência da brucelose humana é encontrada em regiões onde existem costumes de consumir leites de cabra e bovino crus ou queijos macios preparados com leite não pasteurizado (BRICKER et al., 2003). Importante ressaltar que esta doença em humanos é rara em países que adotaram programas de erradicação 
(principalmente vacinação), contra brucelose bovina, ovina e caprina, entretanto, continua endêmica, na Bacia Mediterrânea, Centro Leste, Oeste da África e América do Sul (MAURIN, 2005).

\subsection{DIAGNÓSTICO}

\subsubsection{Métodos indiretos}

Embora sejam predominantemente direcionados para a pesquisa de anticorpos contra Brucella spp no soro, podem ser detectados em vários fluídos corporais. Existe intensa atividade científica visando o desenvolvimento e aperfeiçoamento de testes indiretos para brucelose bovina e os melhores deles estão referenciados e detalhados no Manual de Procedimentos para Testes Diagnósticos e Vacinas da Organização Mundial de Saúde Animal - OIE (www.oie.int).

Os principais testes para diagnosticar a brucelose bovina são: Soroaglutinação Lenta em Tubos(SLT), Soroaglutinação Rápida em Placa(SRP), Teste do Antígeno Acidificado tamponado ou Teste Rosa Bengala (AAT ou TRB), Reação de Fixação do Complemento(FC), Teste do 2-Mercaptoetanol(2-ME), Imunodifusão Radial Dupla, Testes Imunoenzimáticos (ELISA), Teste de Polarização da Fluorescência, Teste do Anel em Leite (TAL), Brucelina, Sêmen-plasma Aglutinação. A quantidade de testes é bastante ampla, sendo assim, cada país de acordo com sua disponibilidade, deve escolher os que melhor se adaptem à sua estratégia (www.oie.int). A OIE admite como teste de referência para comércio internacional e para a confirmação de diagnóstico a reação de FC e como teste de triagem o TRB.

No Brasil, o Programa Nacional de Controle e Erradicação da Brucelose e Tuberculose (PNCEBT), definiu como teste individual de triagem o AAT e como confirmatórios os testes 2-ME e FC. Permite ainda o TAL para detecção de rebanhos infectados (LAGE, 2006). 
Os testes sorológicos são utilizados nas rotinas de certificação de rebanhos livres (www.oie.int).

\subsubsection{Métodos diretos}

Os métodos diretos de diagnóstico para brucelose são utilizados para confirmação de focos bacteriológicos da doença e caracterização do agente circulante, embora resultados negativos não garantam a ausência da doença. Classicamente é realizado a partir do isolamento e identificação do agente e suas espécies. Porém, a reação em cadeia pela polimerase também vem sendo muito utilizada como ferramenta para individualizar a Brucella spp em materiais suspeitos. Em caso de abortamento, recomenda-se a colheita de conteúdo gástrico, fígado, baço, rins e pulmão do feto abortado e dos linfonodos retrofaríngeos, mandibulares, parotídeos, supramamários, do úbere e cotilédone das carcaças de adultos para exame direto. Se o animal suspeito estiver vivo, pode-se tentar isolar a bactéria do leite, de muco vaginal e sêmen. (PAULIN; FERREIRA NETO, 2003).

No exame bacteriológico, os materiais suspeitos são semeados em meios de cultura especiais para multiplicação de Brucella spp, dentre os meios utilizados destacam-se o Ágar Triptose e o Ágar-Brucella. O crescimento desta bactéria é lento, sendo assim, leva-se de 3 a 7 dias para que as colônias possam ser visualizadas (CARTER; CHENGAPPA, 1991). A identificação das espécies de Brucella spp pode ser feita através de provas bioquímicas que identificam diferenças metabólicas entre as espécies e biotipos. As principais provas são: necessidade de $\mathrm{CO} 2$, presença de $\mathrm{H} 2 \mathrm{~S}$, tionina, fucsina básica, aglutinação em soro, tempo de atividade da uréase entre outras (ALTON et al., 1975; METCALF et al., 1994). Uma vantagem deste método direto é a especificidade em detectar a presença da bactéria e as principais desvantagens são os riscos de contaminação acidental em laboratório e o tempo de crescimento bacteriano.

A PCR é uma técnica alternativa ou complementar ao isolamento, capaz de detectar um segmento de DNA específico de B. abortus em materiais suspeitos. Suas principais vantagens são: rapidez quando comparada ao isolamento, alta especificidade pela utilização de primers específicos com seqüências de DNA 
presentes na bactéria e alta sensibilidade (BRICKER, 2002; DAHOUK, 2003; LAGE, 2006). As principais desvantagens deste método são a presença de fatores inibidores do ácido nucléico e o alto custo de equipamentos e reagentes (PAULIN; FERREIRA NETO).

\subsection{CONTROLE}

As estratégias de controle da brucelose visam à redução constante do número de focos da doença. Basicamente, isso é feito com a vacinação das fêmeas, o controle do trânsito dos animais de reprodução e a certificação de rebanhos livres, realizada pelo diagnóstico sistemático dos animais de reprodução, seguido do sacrifício dos positivos, combinados com medidas ambientais. O propósito da vacinação é reduzir a prevalência da doença com baixo custo. Os melhores resultados são alcançados quando cerca de $80 \%$ das fêmeas em idade de procriar estiverem imunizadas. A experiência internacional mostrou que quando essa cobertura vacinal for alcançada, a prevalência dos animais será inferior a $2 \%$ (PAULIN; FERREIRA NETO, 2003).

A vacina mais utilizada nos programas de controle é a B19, uma amostra lisa de B.abortus, naturalmente atenuada, que induz formação de anticorpos contra LPS liso, podendo interferir no diagnóstico da doença. A presença destes anticorpos está relacionada com a idade da vacinação, por isso, esta vacina deve ser empregada somente em fêmeas jovens com até 8 meses de idade. Não se recomenda a vacinação de machos ou fêmeas em gestação. Em meados dos anos 1990 foi desenvolvida uma nova vacina, a RB51, uma amostra de B. abortus rugosa, atenuada, originária de cepa 2308, que diminuiu sua virulência após sofrer inúmeras passagens em meio contendo rifampicina. Por ser rugosa, não provoca formação de anticorpos contra LPS liso, desta forma, não interfere no diagnóstico sorológico da doença (LAGE, 2006). Alguns países já permitem a sua utilização, em combinação ou não com a B19.

Atingida uma situação de baixa prevalência, a vacinação torna-se desnecessária, e as estratégias de controle devem ser trocadas pelas de erradicação, cujo objetivo passa a ser não apenas diminuição constante do número 
de focos, mas a eliminação de todos os focos. Dentre as estratégias de erradicação, destaca-se a detecção dos focos residuais. Essa detecção pode ser feita de várias maneiras: pesquisa de anticorpos no leite, sorologia em animais de reprodução descartados em abatedouro, sorologia para a movimentação de animais de reprodução, estudos por amostragem, busca ativa nos produtores informais, investigação de denúncias ou rumores, investigação de casos de brucelose humana, investigação de propriedades que mantém relação epidemiológica com o foco e, finalmente, investigação de abortos bovinos (PAULIN; FERREIRA NETO, 2003).

O ideal é que seja feita uma investigação bacteriológica nos abortos bovinos antes da intervenção na propriedade. Em caso de resultado positivo, haverá certeza da condição de foco da propriedade. A PCR pode melhorar a performance desse diagnóstico (PAULIN; FERREIRA NETO, 2003).

\section{MATERIAL E MÉTODOS}

\subsection{COMENTÁRIOS INICIAIS}

Tendo em vista o aproveitamento dos dados produzidos em 1998, os cálculos das prevalências nos animais para os circuitos leiteiros ficaram comprometidos pela impossibilidade de se ponderar os resultados pelo número de animais existentes nas propriedades amostradas. Além disso, o estudo dos fatores de risco não foi o mesmo, pois os questionários utilizados em 1998 e nos estudos realizados a partir de 2003 foram diferentes. Entretanto, os resultados produzidos revelaram de forma clara e objetiva a situação da brucelose bovina no Estado naquele ano.

\subsection{LOGÍSTICA}

O estudo foi planejado por técnicos do MAPA em colaboração com os da Agência Estadual de Defesa Sanitária Animal e Vegetal do Mato Grosso do Sul (IAGRO).

O trabalho de campo foi realizado por técnicos da IAGRO, no período de maio a outubro de 1998. Em cada propriedade amostrada, além da colheita de sangue 
para a sorologia, foi também aplicado o questionário epidemiológico, elaborado para obter informações sobre sua tipologia e práticas de manejo empregadas, de forma a permitir a realização do estudo de fatores de risco associados à presença da brucelose. As amostras de sangue foram colhidas por punção da veia jugular dos animais com agulha descartável estéril e tubo com vácuo previamente identificado. As amostras de soro obtidas foram armazenadas em microtubos de plástico e congeladas $\mathrm{a}-20^{\circ} \mathrm{C}$ até o momento da realização dos testes sorológicos.

Os testes sorológicos foram realizados pela IAGRO, com o apoio da Universidade Federal de Mato Grosso do Sul.

Todas as informações geradas pelo trabalho de campo e de laboratório (resultados dos testes sorológicos e questionário epidemiológico) foram inseridas em um banco de dados específico, utilizado para as análises epidemiológicas.

\subsection{DELINEAMENTO AMOSTRAL}

Cabe ressaltar, que o delineamento amostral e o conteúdo investigado pelo questionário, foi estabelecido pela IAGRO na ocasião da realização do estudo, e o banco de dados já veio pronto e estratificado em Pantanal Corte, Planalto Corte e Planalto Leite, não havendo a possibilidade de se estabelecerem criações com tipo de exploração mista.

Para se conhecer as diferenças regionais nos parâmetros epidemiológicos da brucelose bovina, o Estado foi dividido em estratos, levando-se em consideração os diferentes sistemas de produção, práticas de manejo, finalidades de exploração, tamanho médio de rebanhos e sistemas de comercialização. A capacidade operacional do serviço veterinário oficial do Estado também foi levada em consideração para essa tarefa.

Em cada estrato, foi estimada a prevalência de propriedades infectadas pela brucelose bovina e de animais soropositivos através de um estudo amostral em dois estágios, dirigido a detectar focos da doença. No primeiro estágio foram sorteadas, de forma aleatória, um número pré-estabelecido de propriedades com atividade reprodutiva (unidades primárias de amostragem). No segundo estágio, dentro de cada propriedade, foi sorteado um número pré-estabelecido de fêmeas bovinas com idade igual ou superior a 24 meses (unidades secundárias de amostragem). 
Nas propriedades rurais onde existia mais de um rebanho, foi escolhido como alvo do estudo o rebanho bovino de maior importância econômica, no qual os animais estavam submetidos ao mesmo manejo, ou seja, sob as mesmas condições de risco. A escolha da unidade primária de amostragem foi aleatória sistemática, baseada no cadastro de propriedades rurais com atividade reprodutiva de bovinos. Se uma propriedade sorteada não pôde, por quaisquer motivos, ser visitada, foi substituída por outra, nas proximidades e com as mesmas características de produção.

O número de propriedades selecionadas por circuito foi estimado pela fórmula para amostras simples aleatórias proposta por Thrusfield (1995). Os parâmetros adotados para o cálculo foram: nível de confiança de 0,95, prevalência estimada de 0,25 e erro de 0,05 . A capacidade operacional e financeira do serviço veterinário oficial do Estado também foram levadas em consideração para a determinação do tamanho da amostra por estrato.

O planejamento amostral para as unidades secundárias visou estimar um número mínimo de animais a ser examinado dentro de cada propriedade, de forma a permitir a sua classificação como foco ou não foco de brucelose. Para tanto, foi utilizado o conceito de sensibilidade e especificidade agregadas. Para efeito dos cálculos foram adotados os valores de 95,0\% e 99,0\%, respectivamente, para a sensibilidade e a especificidade do teste utilizado (Fletcher et al., 1998) e 20\% para a prevalência intra-rebanho estimada. Nesse processo foi utilizado o programa ${ }^{1}$ Herdacc versão 3 e o tamanho da amostra escolhido foi aquele que permitiu valores de sensibilidade e especificidade de rebanho superiores a $85 \%$.

Operacionalmente, foram amostradas 15 fêmeas com idade igual ou superior a 24 meses por propriedade e, naquelas com menos de 15 fêmeas, a totalidade de animais. A escolha das fêmeas dentro das propriedades foi aleatória.

\subsection{SOROLOGIA}

As amostras foram submetidas ao teste do Antígeno Acidificado Tamponado (AAT) ou teste Rosa Bengala, executado conforme Alton et al. (1988).

Uma propriedade foi considerada positiva quando ao menos um animal positivo foi detectado.

\footnotetext{
${ }^{1}$ BOTENE “comunicação pessoal”, 2008, IAGRO-MS. BRASIL
} 


\subsection{CÁLCULO DAS PREVALÊNCIAS}

A prevalência de focos de brucelose foi calculada para todo o Estado e também para os estratos. Em função das informações disponíveis no banco de dados, só foi possível calcular as prevalências dos animais para os estratos Corte Planalto e Corte Pantanal, já que não havia o número de fêmeas por propriedade. As prevalências aparentes e os respectivos intervalos de confiança foram cálculados conforme preconizado por Dean et al. (1994), com o auxílio do programa Epilnfo $6.04 \mathrm{~d}$.

As prevalências de focos para todo o Estado e para os estratos foram calculadas de forma ponderada, conforme preconizado por Dohoo et al. (2003).

O peso de cada propriedade no cálculo da prevalência de focos para todo o Estado e para os estratos corte (total) e leite (total) foi dado por

$$
P_{1}=\frac{\text { propriedades no estrato/região }}{\text { propriedades amostradas no estrato/região }}
$$

O peso de cada animal no cálculo da prevalência de animais nos estratos Corte Pantanal e Corte Planalto foi dado por

$$
P_{2}=\frac{\text { fêmeas } \geq 24 \text { meses na propriedade }}{\text { fêmeas } \geq 24 \text { meses amostradas na propriedade }}
$$

\subsection{ESTUDO DOS FATORES DE RISCO}

Para os dados consolidados para todo o Estado, foi realizado um estudo de fatores de risco do tipo transversal. As variáveis analisadas foram: número de vacas com idade superior a 24 meses, uso de inseminação artificial e ocorrência de problemas reprodutivos (aborto, retenção de placenta, repetição de cio, nascimento de bezerros fracos e orquite). 
As categorias das variáveis foram organizadas de modo a apresentarem-se em escala crescente de risco, segundo informações da literatura (SALMAN et al., 1984; VASCONCELLOS et al., 1987; BEER, 1988; CRAWFORD et al., 1990; ITO et al., 1998; ACHA; SZYFRES, 2001; PAULIN; FERREIRA NETO, 2003). Quando necessário, realizou-se a recategorização dessas variáveis. A categoria de menor risco foi considerada como base para a comparação das demais categorias. As variáveis quantitativas foram categorizadas em percentis.

Foi feita uma primeira análise exploratória dos dados (univariada) para seleção daquelas com $p \leq 0,20$ para o teste do $\chi^{2}$ ou exato de Fisher (ZAR, 1996) e subseqüente oferecimento destas à regressão logística (HOSMER; LEMESHOW, 1989). Os cálculos foram realizados com o auxílio do programa SPSS version 9.0. 


\section{RESULTADOS}

\subsection{CIRCUITOS PRODUTORES}

O Estado foi dividido em dois diferentes estratos: corte e leite. O estrato corte foi subdividido em duas regiões, a saber, Pantanal e Planalto, e o de leite em três bacias leiteiras, a saber, Bolsão, Campo Grande e Dourados (Figuras 1 e 2). Os dados censitários tomados como base para os cálculos da amostra e das prevalências foram os mais atualizados disponíveis à época do trabalho de campo, ou seja, no ano de 1998.

A Tabela 1 traz um resumo desses dados censitários e também a amostra estudada em cada um dos circuitos produtores.

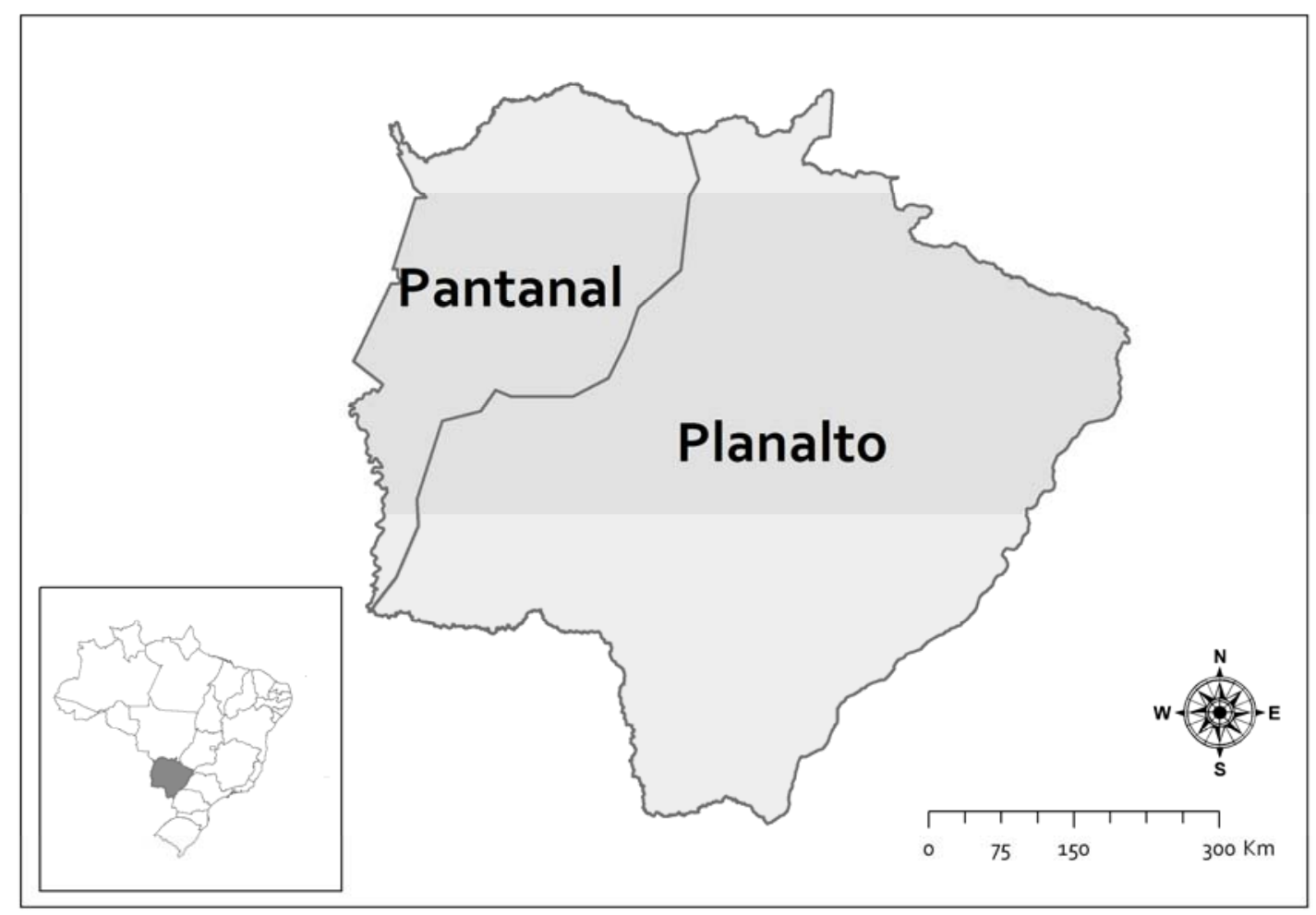

Figura 1- Mapa do Estado do Mato Grosso do Sul evidenciando o estrato corte, dividido nas regiões Pantanal e Planalto. 


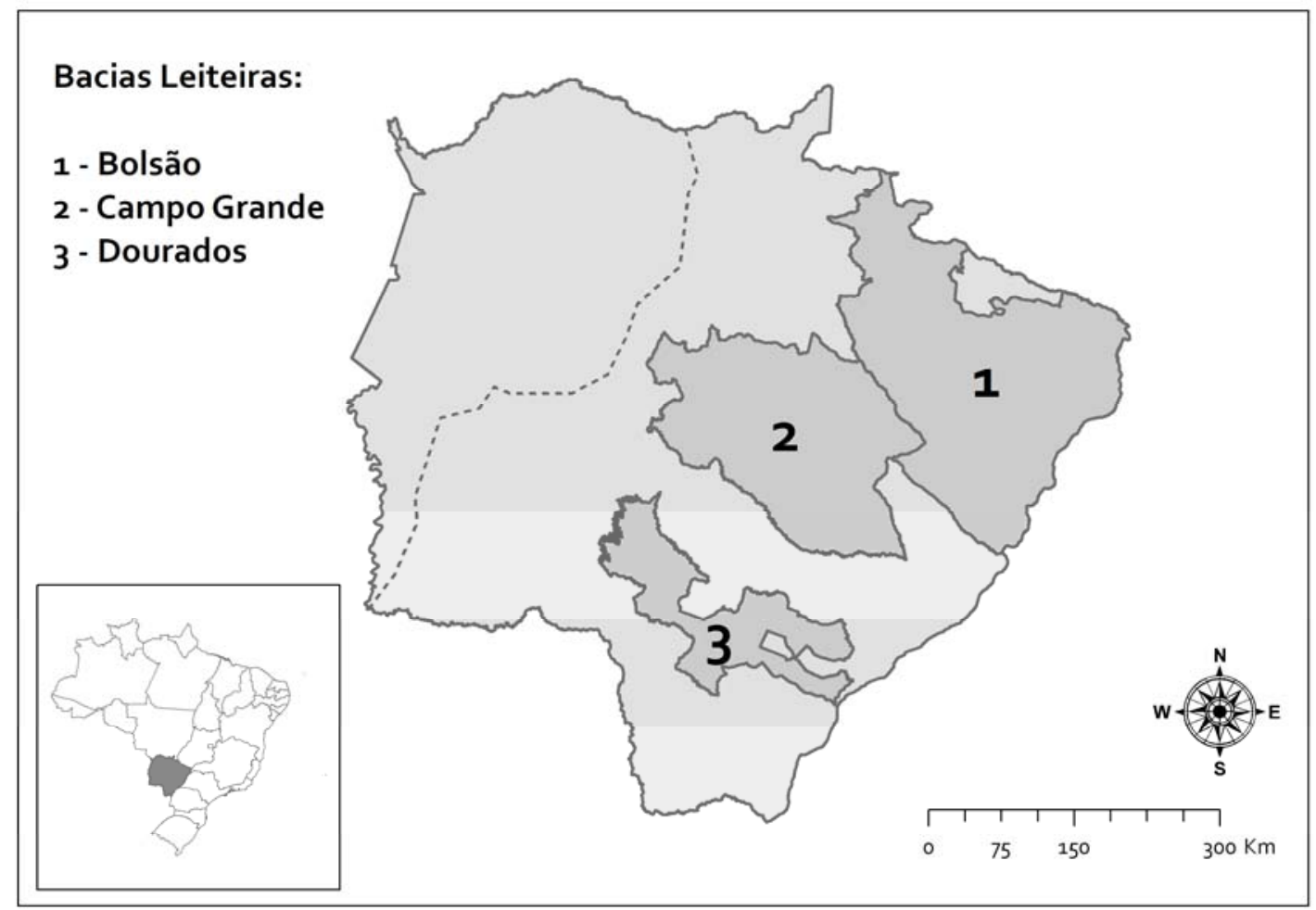

Figura 2- Mapa do Estado do Mato Grosso do Sul evidenciando o estrato leite, composto pelas bacias leiteiras Bolsão, Campo Grande e Dourados.

Tabela 1- Dados censitários da população bovina do Estado do Mato Grosso do Sul em 1998, segundo os estratos (dados do cadastro do IAGRO).

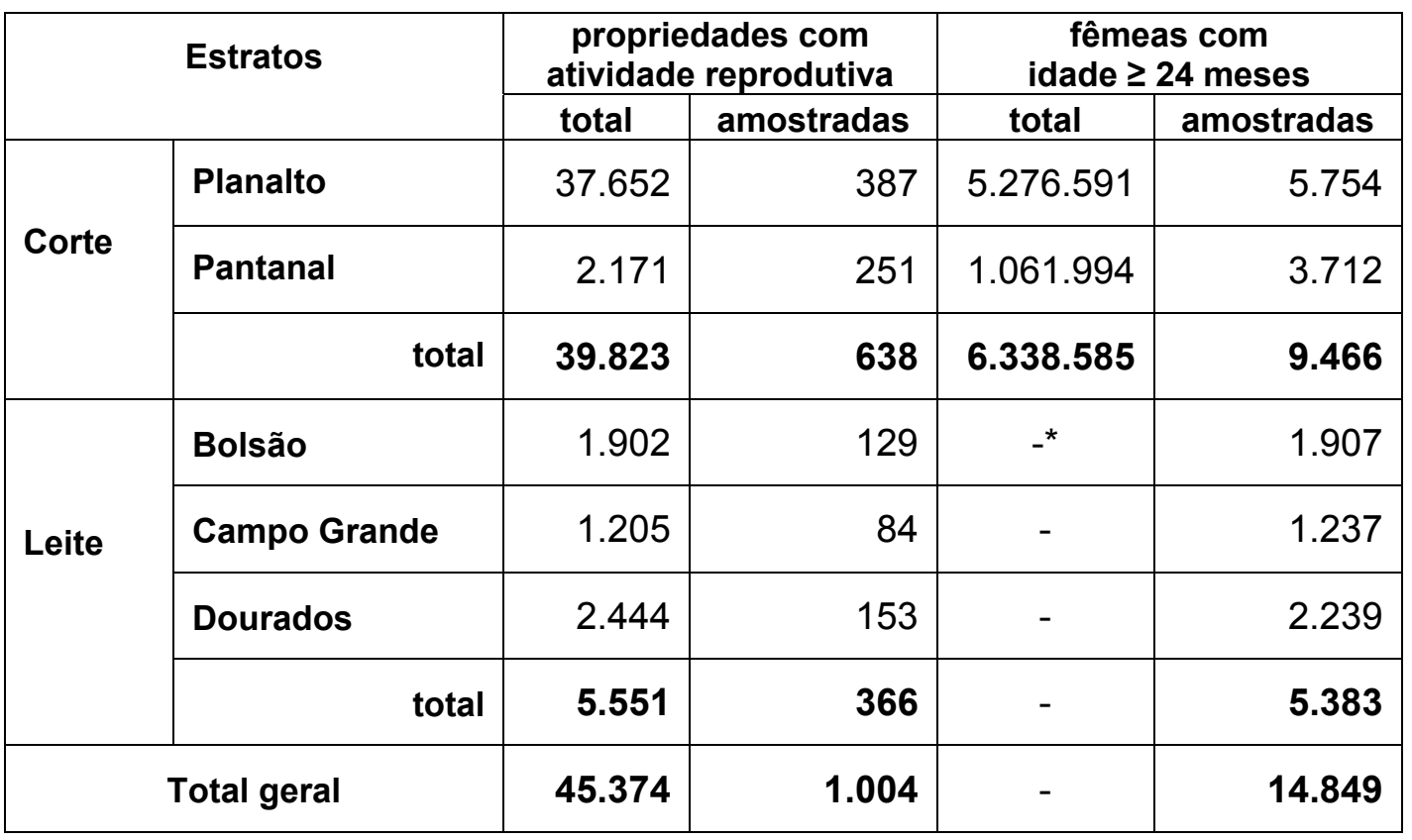

* dado indisponível 
Com base na amostra, foram calculadas as medianas do número de fêmeas com idade $\geq 24$ meses para os vários estratos. A mediana de matrizes no estrato Corte Pantanal foi de 400, no Corte Planalto de 245 e no Leite (total) de 55.

\subsection{PREVALÊNCIAS}

A Tabela 2 mostra os resultados das prevalências de focos no Estado e nos estratos. A Tabela 3 traz as prevalências nos animais para os estratos de gado de corte.

Tabela 2- Prevalência de focos de brucelose nos estratos do Estado do Mato Grosso do Sul.

\begin{tabular}{|c|c|c|c|c|c|}
\hline & \multirow{2}{*}{ Estratos } & \multicolumn{2}{|c|}{ Propriedades } & \multirow{2}{*}{$\begin{array}{c}\text { Prevalência } \\
(\%)\end{array}$} & \multirow{2}{*}{$\begin{array}{c}\text { IC } 95 \% \\
(\%)\end{array}$} \\
\hline & & Testadas & Positivas & & \\
\hline \multirow{3}{*}{ Corte } & Planalto & 387 & 157 & 40.6 & $\lceil 35.8-45.5\rceil$ \\
\hline & Pantanal & 251 & 148 & 59,0 & $\lceil 52,8-64,9\rceil$ \\
\hline & total corte & 638 & 305 & 41,6 & {$[37,0-46,3]$} \\
\hline \multirow{4}{*}{ Leite } & Bolsão & 129 & 37 & 28.7 & $\lceil 21.5-37.1\rceil$ \\
\hline & Campo Grande & 84 & 32 & 38,1 & $\lceil 28,4-48,9\rceil$ \\
\hline & Dourados & 153 & 52 & 34,0 & $\lceil 26,9-41,9\rceil$ \\
\hline & total leite & 366 & 121 & 33,1 & {$[28,4-38,1]$} \\
\hline & Total Estado & 1.004 & 40.5 & 41.5 & {$[36.5-44.71$} \\
\hline
\end{tabular}

Tabela 3- Prevalência de brucelose nos bovinos dos estratos do Estado do Mato Grosso do Sul.

\begin{tabular}{|cc|c|c|c|c|}
\hline \multirow{2}{*}{ Estratos } & \multicolumn{2}{|c|}{ Animais } & \multirow{2}{*}{ Prevalência (\%) } & IC 95\% (\%) \\
\cline { 3 - 4 } & Testados & Positivos & & \\
\hline \multirow{2}{*}{ Corte } & Planalto & 5.754 & 259 & 4.5 & $\lceil 2.1-9.01$ \\
& Pantanal & 3.712 & 468 & 12,6 & $\lceil 9,1-17,2]$ \\
\hline
\end{tabular}




\subsection{ANÁLISE DOS FATORES DE RISCO}

A Tabela 4 mostra os resultados da análise univariada e a Tabela 5 o modelo final da regressão logística.

Tabela 4- Análise univariada dos possíveis fatores associados à condição de foco de brucelose bovina no Estado do Mato Grosso do Sul.

\begin{tabular}{lccc}
\hline Variável & $\begin{array}{c}\text { Expostos/Cas } \\
\text { os }\end{array}$ & $\begin{array}{c}\text { Expostos } \\
\text { /Controles }\end{array}$ & Valor de p \\
\hline Apresentou problema reprodutivo & $233 / 550$ & $133 / 318$ & 0,877 \\
$\begin{array}{l}\text { Reportou ocorrência de aborto } \\
\text { Reportou ocorrência de retenção de }\end{array}$ & $163 / 372$ & $240 / 575$ & 0,528 \\
-1- & $152 / 372$ & $244 / 551$ & 0,303 \\
Reportou ocorrência de repetição de cio & $149 / 358$ & $234 / 548$ & 0,748 \\
Reportou ocorrência de bezerros fracos & $97 / 207$ & $294 / 710$ & 0,163 \\
Usa inseminação artificial & $8 / 22$ & $382 / 886$ & 0,527 \\
Tem $\geq 500$ vacas & $67 / 180$ & $359 / 824$ & 0,119 \\
\hline
\end{tabular}

Tabela 5- Modelo final da regressão logística multivariada para os fatores associados à condição de foco de brucelose bovina no Estado do Mato Grosso do Sul.

\begin{tabular}{lccc}
\hline \multicolumn{1}{c}{ Variáveis } & OR & IC95\% & Vapor de p \\
\hline Ter $\geq 500$ vacas & 2,46 & $1,81-3,34$ & 0,001 \\
Uso de inseminação artificial & 0,71 & $0,50-1,01$ & 0,056 \\
Reportou ocorrência de bezerros fracos & 1,20 & $0,87-1,65$ & 0,259 \\
\hline
\end{tabular}




\section{DISCUSSÃO}

\subsection{PREVALÊNCIAS}

Na tabela 2, verifica-se que o Estado apresentou altas prevalências de focos e que existiu evidente tendência de serem mais elevadas nos estratos de corte. A prevalência de focos no estrato Corte Pantanal foi estatisticamente superior a de todos os demais. Esse mesmo estrato também mostrou uma prevalência de animais estatisticamente superior a do estrato Corte Planalto (Tabela 3). Importante dizer que essas prevalências de focos elevadas são em parte conseqüência do modo de produção do Estado, organizado principalmente em grandes propriedades, com número elevado de matrizes. A mediana de matrizes no estrato Corte Pantanal foi de 400, no Corte Planalto de 245 e no Leite Planalto de 55. Nesse caso, existe uma tendência da prevalência de focos resultar elevada, pois basta um animal positivo para classificar toda a unidade de produção como foco, ou seja, uma mesma prevalência de animais tende a determinar prevalências de focos mais elevadas em regiões de propriedades grandes, com um número elevado de animais, do que em regiões de propriedades pequenas com um pequeno número de animais.

$\mathrm{Na}$ mesma tabela 2, verifica-se que as três grandes bacias leiteiras do Estado, localizadas nas regiões do Bolsão, Dourados e Campo Grande, apresentaram a mesma prevalência de focos de brucelose, apesar das estimativas pontuais mostrarem-se diferentes. Também não houve diferença entre as prevalências de focos dessas três regiões leiteiras e aquela verificada no estrato Corte Planalto, apesar dos números absolutos serem maiores para esse último.

Tratando-se de prevalência de focos, foi possível concluir que em 1998 existia forte tendência de maior concentração da doença nas propriedades de corte, com destaque para o estrato Corte Pantanal e que a situação era homogênea nas três principais bacias leiteiras do Estado. Isso pode ser em decorrência do tamanho grande dos rebanhos de corte, significando intenso trânsito de animais, com subseqüente aumento do risco de introdução e exportação da doença e também do melhor trabalho desenvolvido pelas cooperativas leiteiras do Estado (POESTER et. al, 2002). 
Para melhor encaminhar a discussão, utilizaremos o quadro 1 (página 14), que traz um resumo dos principais estudos de prevalência realizados no Estado.

Por tratar-se de Estado criado em 1979, a partir da divisão do antigo Estado de Mato Grosso, torna-se importante saber se a situação da brucelose nos dois Estados é semelhante. Os dados indicam que a situação é bastante parecida, pois a prevalência de focos no MS em 1997 foi de 41,5\% (Tabela 2) e de 42,2\% no MT em 2003 (INDEA, 2004). Feita essa ressalva, é possível comparar estudos realizados no antigo Estado do Mato Grosso com aqueles realizados no atual Estado do Mato Grosso do Sul.

O grande estudo realizado pelo MAPA em 1975 mostrou que a prevalência de focos no antigo Estado de Mato Grosso foi de 22,9\%, muito inferior à verificada pelo presente para o ano de 1997 (41,5\%, Tab. 2). Em que pese a diferença metodológica, tanto no planejamento amostral quanto nos protocolos de testes empregados nos dois estudos, é razoável supor que a prevalência realmente aumentou no Estado, pois o efetivo bovino aumentou cerca de 3,6 vezes no período, de 6 para 21 milhões de cabeças (www.ibge.gov.br), e com ela o trânsito de animais. Essa situação, somada à ausência de programa organizado de combate à brucelose, resultou invariavelmente no espalhamento da doença. Em 1975 a prevalência de animais foi de 6,25\% (MAPA, 1977) e em 2001 havia subido para $8,6 \%$ (ALMEIDA, 2001), sugerindo aumento da prevalência a despeito das diferenças metodológicas dos dois estudos.

Para a região do Pantanal, Cavalléro (1998) obteve uma prevalência de $10,19 \%$ de animais positivos no período de 1982 a 1984, muito diferente da encontrada em estudo subseqüente, realizado por Pellegrin et al. (1999), onde a prevalência de animais foi de 3,43\% para o período de 1994 a 1996 . Essa grande diferença pode ser decorrente do reduzido número de animais amostrados (309) no estudo de 1999, em relação aos 1942 amostrados no estudo de Cavalléro (1998). A prevalência nos animais encontrada no período de 1982 a 1984 (10,19\%) é muito semelhante à verificada pelo presente estudo para o ano de 1998 (12,6\%, Tabela 3). Ao que parece, o Pantanal mato-grossense está em situação de equilíbrio, onde o número de animais que se infectam é igual ao número de animais infectados que morrem, já que desde 1982 a prevalência permanece praticamente a mesma. 
Na região do Planalto, Monteiro et al. (2006), realizando as coletas de sangue entre 2003 e 2004 em amostra sem estratificação para corte e leite, estimou a prevalência de focos em $37,3 \%$, valor intermediário às prevalências de focos de $33,1 \%$ e 40,6\%, estimadas respectivamente para as propriedades de leite e corte no presente estudo, ou seja, para coletas de sangue realizadas no ano de 1997 (Tabela 2). As prevalências de animais encontradas pelos dois estudos também foram próximas: 4,5\% em 1997 para as propriedades de corte (Tabela 3) e 5,6\% em 2003/2004 para propriedades de corte ou leite (MONTEIRO et al., 2006).

Em resumo, esses dados sugerem que a prevalência da brucelose em MS vinha aumentando até por volta das décadas de 1980/1990 e desde então tem apresentado uma situação de relativo equilíbrio, com alta prevalência de focos.

A forma mais eficiente e econômica para o Estado rebaixar a prevalência de brucelose é através da vacinação, todos os anos, de no mínimo $80 \%$ de bezerras entre 3 a 8 meses com a amostra B19.

\subsection{FATORES DE RISCO}

A ocorrência de bezerros fracos, embora tenha apresentado um $p=0,25$, foi mantida no modelo final como variável de ajuste pela plausibilidade biológica e por apresentar um intervalo de OR próximo ao limite da significância $(0,87 \leq \mathrm{IC} 95 \% \leq 1,65$, Tabela 5). Assim, o modelo final da regressão logística mostrou que ter 500 ou mais vacas e verificar a ocorrência de bezerros fracos foram fatores associados à condição de foco de brucelose bovina no Estado. O uso da inseminação artificial mostrou-se um fator protetor (Tabela 6).

A associação entre o tamanho de rebanho e a presença de brucelose foi demonstrada em vários estudos (KELLAR et al., 1976; NICOLETTI 1980; SALMAN; MEYER, 1984). Os animais provenientes de rebanhos grandes não têm diferenças individuais quanto à suscetibilidade da doença, mas algumas características desses grandes rebanhos podem facilitar a transmissão da brucelose, tais como: maior freqüência de reposição de animais, maior quantidade de problemas relacionados ao 
controle sanitário e a influência na dinâmica da doença (CRAWFORD et al., 1990). Christie (1969) observou que, com o aumento do rebanho, aumenta a probabilidade e persistência de infecção, prevalência da doença e dificuldade de erradicação. Assim, número elevado de animais no rebanho significa, na verdade, maior risco de introdução e espalhamento da brucelose. Importante ressaltar que ter mais de 500 vacas no rebanho, praticamente significa ser propriedade de corte no MS, pois $96 \%$ (242/252) das propriedades com mais de 500 vacas eram de corte. Esses dados corroboram os resultados obtidos no estudo das prevalências, onde foi verificada uma maior concentração da infecção nos estratos de propriedades de corte.

A associação de nascimento de bezerros fracos com a condição de foco de brucelose bovina já foi relatada por vários autores (NICOLETTI, 1986; SAMARTINO, ENRIGHT,1993; THOEN et. al, 1993), já que as diferenças de manifestações clínicas são decorrentes do desenvolvimento de imunidade. O aborto é um acontecimento constante na primeira gestação e nas gestações subseqüentes o mais comum é o nascimento de animais fracos, pois um menor número de placentomas é atingido e menor é o grau de lesão observado. Portanto, a diminuição da passagem de nutrientes e oxigênio não chega a causar a morte do feto, mas um menor desenvolvimento do mesmo, o que se traduz pelo nascimento de animais pequenos e subdesenvolvidos (PELLEGRIN et. al, 2006). Assim, a ocorrência de nascimento de bezerros fracos é uma conseqüência da brucelose.

O uso da inseminação artificial mostrou uma Odds Ratio inferior a um e no limite da significância, informando que essa prática está associada à condição de livre de brucelose. Essa variável é freqüentemente utilizada como indicador do nível de tecnificação da produção, significando capacidade de incorporação de tecnologias e, por conseqüência, de práticas sanitárias mais acuradas. Assim, esse resultado indica que propriedades mais bem estruturadas do ponto de vista zootécnico e sanitário têm uma menor chance de serem focos de brucelose.

Esses resultados sugerem que o fator mais importante para o espalhamento da brucelose no Estado é a introdução de animais sem cuidados sanitários, que emergiu de forma indireta, pela interpretação da variável "ter 500 ou mais vacas". 


\subsection{RECOMENDAÇÕES PARA O ESTADO}

- Concentrar esforços na obtenção, todos os anos, de uma cobertura vacinal mínima de $80 \%$ de fêmeas entre 3 e 8 meses de idade com a vacina B19;

- Desencorajar a introdução de animais sem cuidados sanitários.

Agradecimentos: à FAPESP, ao CNPq e ao MAPA pelo apoio financeiro. 


\section{REFERÊNCIAS BIBLIOGRÁFICAS}

ACHA, P.N.; SZYFRES, B. Zoonosis y enfermedades transmisibles comunes al hombre y a los animales: bacterioses e micoses 3 .ed. Washington: OPAS, 2001. $416 \mathrm{p}$.

ALMEIDA, R. C. F. Diagnóstico da brucelose e tuberculose bovina. 2001. 30 p. Monografia (Graduação)- Universidade Federal de Mato Grosso do Sul, Campo Grande, 2001.

ALTON, G. G.; JONES M. L.; PIETZ D. E. Las tecnicas de laboratorio em la brucelosis. Ginebra: OMS, 1975. p. 79-126.

ALTON, G. G.; JONES, L. M.; ANGUS, R. D.; VERGER, J. M. Techniques for the brucellosis laboratory. Paris: Intitut National de la Recherche Agronomique, 1988. $545 \mathrm{p}$.

BRASIL. Ministério da Agricultura e Abastecimento. Diagnóstico de Saúde Animal, Brasília. 1977, $735 \mathrm{p}$.

BRASIL. Ministério da Agricultura e Abastecimento. Programa Nacional de Controle e Erradicação da Brucelose e Tuberculose. Brasília. Disponível em: $<$ http://www.agricultura.gov.br/das/dda/programa.htm> 2001. Acessado em :7 abr. 2004.

CAMPERO, C. M. Brucelosis en toros: uma revisión. Vet. Méd., Buenos Aires, v.74, p.8-14, 1993.

CARTER, G. R.; CHENGAPPA, M. M. Essentials of veterinary bacteriology and mycology. Filadelfia: Lea \& Febiger, 1991. p. 196-200.

CAVALLÉRO, J. C. M. Enfermidades causadoras de aborto: brucelose. In: LEMOS, R. A. A. (Ed). Principais enfermidades de bovinos de borte do Mato Grosso do Sul: Reconhecimento e diagnóstico. Campo Grande: Universidade Federal de Mato Grosso do Sul,1998, 536 p.

CHU, M. C.; WEYANT, R. S. Francisella and Brucella. In: MURRAY, P. R.;

BARON, E. J.; JORGENSON, J. H.; PFALLER, M. A.; YOLKEN, R. H. Manual of

Clinical Microbiology. 8. ed. Washington: ASM Press, 2003. p. 789-804.

CIPOLLA, A.; SALUSTIO, E.; BOSCHIROLI, L.; CAMPOS, E.; ODRIOZOLA, E.;CAMPERO, C. L.; SAMARTINO, L.; ROSSETTI, O.; GAGLIARDO,L. 
Caracterizacionbioquímica y molecular de cepas de Brucella abortus aisladas en Argentina. Buenos Aires: InstitutoNacional de Tecnologia Agropecuária. Estación Experimental Agropecuária Balcarce, 2004.

CLOECKAERT, A.; GRAYON, M.; GREPINET, O.; BOUMEDINE, K. S. Classification of Brucella strains isolated from marine mammals by infrequent restriction site-PCR and development of specific PCR identification tests. Microbes and Infection, v. 5, n. 7, p. 593-602, 2003.

COCHRAN, W. G. Sampling techniques. 3. ed. New York: John Wiley \& Sons, 1997. 428 p.

CRAWFORD, R. P.; HUBER, J. D.; ADAMS, B. S. Epidemiology and surveillance. In: NIELSEN, K.; DUNCAN, J. R. Animal brucellosis. Boca Raton: CRC Press, 1990. p. 131-151.

CHRISTIE, T. E. Eradication of brucellosis in northern Ireland: field problems and experiences. Veterinary Record., v. 85, p. 268-269, 1969.

DEAN, A. G.; DEAN, J. A.; COLOMBIER, D. et al. Epi-Info, Version 6: a word processing database, and statistics program for epidemiology on microcomputers. Atlanta: CDC, 1994.601p.

DOHOO, I.; MARTIN, W.; STRYHN, H. Veterinary epidemiologic research. Charlottetown: Atlantic Veterinary College, p. 706, 2003.

ESSELIN, P .M. A pecuária no processo de ocupação e desenvolvimento econômico do Pantanal sul-mato-grossemsse (1830-1910), 2003. 83p. Tese (Doutorado) - pontifícia Universidade Católica do Rio Grande do Sul, Porto Alegre, 2003.

FLETCHER, R. H.; FLETCHER, S. W.; WAGNER, E. H. Clinical epidemiology: the essentials. 2. ed. Baltimore: Williams \& Wilkins, 1998. 246p.

HOSMER JR, D. W.; LEMESHOW, S. Applied logistic regression. New York: Wiley, 1989. $307 \mathrm{p}$.

IBGE. Instituto Brasileiro de Geografia e Bioestatística. Rio de Janeiro: IBGE 2007. Disponível em: <http:www.sidra.ibge.gov.br>. Acessado em: 7 maio 2007.

IKRAM, M.; HILL, E. Microbiology for veterinary technicians. 1. ed. Goleta: American Veterinary Publications, 1991. 
INDEA. Instituto de Defesa Agropecuária do Estado de Mato Grosso. Cuiabá, 2004. Disponível em: http:Ilwww.indea.mt.gov.br/html/index.php

ITO, F. H.; VASCONCELLOS, S. A.; BERNARDI, F. et al. Evidencia sorológica de brucelose e leptospirose e parasitismo por ixodideos em animais silvestres do Pantanal sul-matogrossense. Ars Veterinária, v. 14, n. 3, p. 302-310, 1998.

KELLAR, J.; MARRA, R.; MARTIN, W. Brucellosis in Ontario: a case control study. Canadian Journal of Comparative Medicine, v. 40, p. 119, 1976.

LAGE, A. P.; ROXO, E.; MÜLlER, E.; POESTER, F.; CAVALLÉRO, J. C. M.; FERREIRANETO, J. S.; MOTA, P. M. P. C.; GONÇALVES, V. S. P. Programa nacional de controle e erradicação da brucelose e da tuberculose animal (PNCEBT). 1. ed. Brasília: Ministério da Agricultura, Pecuária e Abastecimento, 2006, 188 p. (Manual Técnico).

LEMOS, R.A.A. Principais Enfermidades de Bovinos de Corte no Estado do Mato Grosso do Sul, Campo Grande: UFMS, 1998. p. 408-441.

MARIANELLI, C.; GRAZIANI, C.; SANTANGELO, C.; XIBILIA, M. T.; AMATO, R.; NERI,D.; CUCCIA, M.; RINNONE, S.; DI MARCO, V.; CIUCHINI, F. Molecular epidemiological and antibiotic susceptibility characterization of brucella isolates from humans in Sicily, Italy. Journal of Clinical Microbiology, v. 45, n. 9, p. 2923-2928, 2007

MATO GROSSO DO SUL. Governo do Estado de Mato Grosso do Sul. Disponível em: http://www.ms.gov.br/index.php?inside=1\&tp=3\&comp=1725\&show=949 Acessado em: 10 out. 2007

MONTEIRO,L. A. R. C., PELlEGRIN, A. O., ISHIKAWA, M .M., OSÓRIO,A. L. A. R. Investigação Epidemiológica da brucelose bovina em um estrato do Estado de Mato Grosso do Sul. Pesquisa Veterinária Brasileira, v.26, n.4, p.217-222 , 2006.

NICOLETTI, P. The epidemiology of bovine brucellosis. Advances in Veterinary Sciences and Comparative Medicine, San Diego, v. 24, p. 69-98, 1980.

NICOLETTI, P. Effects of Brucellosis on bovine reproductive efficiency. In: MORROW, D. A.. Current therapy in theriogenology, 2. ed. p. 271-274, 1986.

NOORDHUIZEN, J. P. T. M.; FRANKENA, K.; VAN DER HOOFD, C .M. et al. Application of quantitative methods in veterinary epidemiology. Wageningen: Wageningen Press, 1997. 445 p. 
OLASCOAGA, C. R. Diagnóstico serologico de la brucelosis. Zoonosis, v. 18, p. 107-141, 1976.

PALMQUIST, K. O. Contribuição ao conhecimento da incidência da brucelose no Estado do Paraná (Brasil). Brazilian Archives of Biology and Technology_. v. 7, p. 3-8, 1952.

PAULIN, L.M.; FERREIRA-NETO, J. S. O combate à brucelose bovina: Situação Brasileira. Jaboticabal: Funep, 2003, 154 p.

PEARCE, J. H.; WILLIANS, A. E.; HARRIS-SMITH, P. W.; FITZGEORGE, R. B.; $\mathrm{SMITH}, \mathrm{H}$. The chemical basis of the virulence of Brucella abortus. II. rytritol, a constituent of bovine foetal fluids which stimulates the growth of Brucella abortus in bovine phagocytes. British Journal of Experimental Pathology, v. 43, p. 31-37, 1961.

PELLEGRIN, A. O., SERENO, J. R. B., SILVA, R. A. M. S., LEITE, R. C. Doenças da reprodução diagnosticadas no pantanal Mato Grossense e região do planalto: Resultados preliminares. In: I ENCONTRO DE LABORATÓRIOS DE DIAGNÓSTICOS VETERINÁRIO DO CONE SUL.1. Campo Grande. Anais... Campo Grande: UFMS, 1996. P. 68-72. Editora da Universidade Federal de Mato Grosso do Sul, p. 68-72, 1996.

PELLEGRIN, A. O.; LEITE, R. M. H; GUIMARÃES, P. H. S..; LAGE, A. P.; LEITE, R. C. Prevalência de brucelose bovina no Panatanal Matogrossense. In: CONGRESSO BRASILEIRO DE MEDICINA VETERINÁRIA, 26, 1999, Campo Grande.

PELLEGRIN, A. O.; LEITE, R. M. H; SERENO, J. R. B.; LAGE, A. P.; LEITE, R. C.; RAVAGLIA, E. Brucelose bovina no Panatanal Sul Mato-Grossense: dados preliminares. Comunicado Técnico, v. 58, p. 1-4, 2006.

POESTER, F. P,GONÇALVES, V. S. P.,LAGE, A. P. Brucellosis in Brazil. Veterinary Microbiology., v. 90, p, 55-62, 2002.

RIEMANN, H. P.; CLIVER, D. O. Foodborne Infections and Intoxications. 3 ed. California: Elsevier Academic Press, 2006, p. 346-347.

SALDARRIAGA, O. A; OSSA, J. E.; RUGELES, M. T. Respuesta inmune y estratégias de evasión durante la infección con Brucella spp. Revista Colombiana de Ciências Pecuárias, v. 15, n. 2, p. 180-187, 2002. 
SALMAN, M. D.; MEYER, M. E. Epidemiology of bovine brucellosis in the Mexicali Valley, México: literature review of disease-associated factors. American Journal of Veterinary Research, v. 45, n 8, p.1557-1560, 1984.

SALMAN, M. D.; MEYER, M. E.; HIRD, D. W. Epidemiology of bovine brucellosis in the Mexicali Valley, México: data gathering and survey results. American Journal of Veterinary Research., v. 45, n 8, p.1561-1566, 1984.

SAMARTINO, L. E.; ENRIGHT, F. M. Pathogenesis of abortion of bovine brucellosis. Comarative Immunology Microbiology Infectious Disease, v. 16, p. $95-101$, 1993.

THRUSFIELD, M. Veterinary Epidemiology. 2. ed. Cambridge: Blackwell Science, 1995. $479 \mathrm{p}$.

TOCANTINS, S. Distribuição espacial da brucelose no gado bovino no pantanal de Mato Grosso e relação com fatores ambientais. Tese de Mestrado. Disponível em: $<$ http://www.cpap.embrapa.br/agencia/congresso/8-25.cintra.htm.

THOEN, C.O.; ENRIGHT, F.; CHEVILLE, N.F. Brucella. In: GYLES, C.L.; THOEN, C.O. Pathogenesis of bacterial infections in animals, 2 ed, p. $236-247,1993$.

TORTORA, G. J; FUNKE, B. R.; CASE, C. L. Microbiologia. 6. ed. Porto Alegre: Artmed,2000. p. 607-609.

VASCONCELLOS, S.A.; ITO, F. H.; CÔRTES, J.A. Bases para a prevenção da brucelose animal. Comunicado Ciêntífico Faculdade de Medicina Veterinária e Zootecnia - USP, v. 11, n.1, p. 25-36, 1987.

ZAR, J. H. Bioestatistical analysis. 3.ed. New Jersey: Prentice-Hall, 1996. 662p. 